\title{
Hg contents of Toarcian sediments from the Marrat Formation, Saudi Arabia
}

\author{
SVETOSLAV V GEORGIEV, ABID KHOGALI AND \\ HASSAN A ELTOM
}

KFUPM

Presenting Author: svetoslav.georgiev@kfupm.edu.sa

The temporal coincidence of large igneous provinces (LIP) with elevated mercury contents and $\mathrm{Hg} / \mathrm{TOC}$ ratios in coeval sediments suggests that sedimentary $\mathrm{Hg}$ is a reliable proxy for volcanic emissions ${ }^{1}$. However, high $\mathrm{Hg}$ loading may also result by increased supply of terestrial organic matter ${ }^{2}$, which may or may not contain $\mathrm{Hg}$ from coeval volcanism. These end-member scenarios and intermediate cases are clearly illustrated in multiple sections deposited during the Early Jurassic Toarcian oceanic anoxic event (T-OAE) that coincides with the eruption of the Karoo-Ferrar LIP ${ }^{1,2}$.

Here, we explore the application of the Hg proxy by studying Toarcian sediments exposed near Riyadh, Saudi Arabia. The Marrat Fm comprises red kaolinite-rich claystones belonging mostly to the Harp. serpentinum ammonite Zone, which are under- and overlain by resistive limestone beds ${ }^{3}$. The sediments are traditionally regarded as marginally marine deposits ${ }^{3}$, although recent studies instead suggest shallow-marine sedimentation for the Marrat Fm claystones ${ }^{4}$.

Preliminary data on 24 pilot samples reveal significant variations in $\mathrm{Hg}$ contents between 0.3 and $17.5 \mathrm{ppb}$, with the highest values detected in specific limestone units. A more detailed study including $\mathrm{Hg}$, TOC, elemental and XRD data and carbon isotopes is being established to explore finer chemostratigraphic details. Our aim is to constrain the depositional conditions for these sediments with a special emphasis on understanding the $\mathrm{Hg}$ host within the rocks. Comparison with published Toarcian profiles can reveal whether the $\mathrm{Hg}$ Toarcian peaks are present in the generally shallow marine and TOC-lean studied section, whereas integration of geochemical and mineralogical data will be used to discern the dominant mechanism for $\mathrm{Hg}$ delivery to sediments. In turn, successful global correlations hold the potential to improve the relatively scarce biostratigraphy of the Marrat Fm.

[1] Percival et al. (2015), EPSL. 428, 267-280.

[2] Them II et al. (2019), EPSL. 507, 62-72.

[3] Al-Mojel et al. (2020), J. Afr. Earth Sci. 167, 103429.

[4] Al-Hussaini et al. (2021), Mar. Petr. Geol. 126, 104915. 